\title{
Implications of market integration for cardiovascular and metabolic health among an indigenous Amazonian Ecuadorian population
}

\author{
Melissa A. Liebert ${ }^{1,2}$, J. Josh Snodgrass ${ }^{1,2}$, Felicia C. Madimenos ${ }^{1,2}$, Tara J. Cepon ${ }^{1,2}$, \\ Aaron D. Blackwell ${ }^{3,4}$ \& Lawrence S. Sugiyama ${ }^{1,2,4}$ \\ ${ }^{1}$ Department of Anthropology, ${ }^{2}$ Institute of Cognitive and Decision Sciences, University of Oregon, Eugene OR, USA, \\ ${ }^{3}$ Department of Anthropology, and ${ }^{4}$ Center for Evolutionary Psychology, University of California, Santa Barbara, CA, USA
}

Background: Market integration (MI), the suite of social and cultural changes that occur with economic development, has been associated with negative health outcomes such as cardiovascular disease; however, key questions remain about how this transition manifests at the local level.

Aim: The present paper investigates the effects of MI on health among Shuar, an indigenous lowland Ecuadorian population, with the goal of better understanding the mechanisms responsible for this health transition.

Subjects and methods: This study examines associations between measures of $\mathrm{Ml}$ and several dimensions of cardiovascular and metabolic health (fasting glucose, lipids [LDL, HDL and total cholesterol; triglycerides] and blood pressure) among 348 adults.

Results: Overall, Shuar males and females have relatively favourable cardiovascular and metabolic health. Shuar who live closer to town have higher total $(p<0.001)$ and HDL cholesterol ( $p<0.001$ ), while Shuar in more remote regions have higher diastolic blood pressure ( $p=0.007)$. HDL cholesterol is positively associated with consumption of market foods ( $r=0.140 ; p=0.045)$ and ownership of consumer products $(r=0.184 ; p=0.029)$.

Conclusions: This study provides evidence that MI among Shuar is not a uniformly negative process but instead produces complex cardiovascular and metabolic health outcomes.

Keywords: Market integration, cardiovascular disease, metabolic disorders, Amazonia

\section{INTRODUCTION}

The recent global increase in chronic, non-communicable conditions such as cardiovascular and metabolic diseases has been a major focus of epidemiological research over the past several decades. Cardiovascular disease (CVD; heart disease and stroke) is now the leading cause of death worldwide, affecting populations in both developed and developing nations (Chobanian et al. 2003; Pollard 2008; WHO 2008). Similarly, metabolic diseases such as type II diabetes (T2D) have increased rapidly throughout the world, with over 360 million individuals projected to have diabetes by 2030 (Hossain et al. 2007). Cardiovascular and metabolic diseases are closely linked with overweight and obesity, which have also increased rapidly in recent years, as over 1.5 billion adults worldwide are currently considered overweight or obese (WHO 2000). Risk factors for CVD and T2D include tobacco use, alcohol consumption, chronic psychosocial stress and physical inactivity, but dietary change associated with increased consumption of energy-dense, highly processed foods is thought to be of prime importance (WHO 2002; Dressler 2004; Pollard 2008). Despite progress on understanding this epidemiological transition, it has been difficult to empirically link regional social and economic changes to individual behaviours and health outcomes. As a result, the specific mechanisms responsible for the recent increase in $\mathrm{CVD}$ and $\mathrm{T} 2 \mathrm{D}$ remain incompletely understood.

Market integration (MI), the suite of social and cultural changes that occur with economic development, is a key factor affecting individual health outcomes among indigenous groups. Although debate exists over how best to conceptualize and operationalize MI (Dressler and Bindon 2000; McDade 2002; Godoy et al. 2005; Lu 2007; Sorensen et al. 2009; McDade and Nyberg 2010), this process involves the emergence of market-based systems of exchange and, specifically, the increased degree of participation in and dependence on markets to obtain food resources (Godoy 2001; Godoy and Cardenas 2000; Godoy et al. 2005; Lu 2007). The transition from a subsistence-based lifestyle to a market economy influences myriad dimensions of life

Correspondence: Melissa A. Liebert, Department of Anthropology, University of Oregon, Eugene, OR 97403, USA. Tel: (541) 346-5102. Fax: (541) 346-0668. E-mail: liebert@uoregon.edu

(Received 20 May 2012; revised 15 November 2012; accepted 12 December 2012) 
(e.g. diet, activity patterns and psychosocial stress) (Friedlaender et al. 1987; McGarvey et al. 1989; HussAshmore et al. 1992; Shephard and Rode 1996; Bindon et al. 1997). There is, however, disagreement about whether MI produces overall negative, positive or mixed effects on health (Godoy and Cardenas 2000; McDade and Nyberg 2010). In many studies, MI has been linked to negative health markers related to CVD and T2D (e.g. high fasting glucose concentrations, elevated plasma lipids, hypertension and obesity) (Baker et al. 1986; Dressler et al. 1987; Gohdes 1995; Bindon 1995; Shephard and Rode 1996; Dressler 1999, 2004; Gurven et al. 2012), whereas, in other studies, MI has been linked with improved growth and lower mortality risk, particularly for children, as a result of increased dietary diversity and access to healthcare (Dennett and Connell 1988; Santos and Coimbra Júnior 1991; Gage 2005). Further, research among groups such as native Siberians has identified a positive correlation between continued participation in subsistence-based lifestyles and elevated risks of CVD (Sorensen et al. 2005). Additional studies have suggested that cultural and economic transitions produce mixed and ambiguous health outcomes, which may change over time due to multiple, conflicting pathways (Berry et al. 1986; Godoy et al. 2005; Steffen et al. 2006). These inconsistent results underscore the need to clarify the multiple social and economic factors that influence health change among populations experiencing MI and to better understand how regional and global factors influence the experience of MI at the household and individual level.

A further complication is that adaptation to local environments may shape how different populations experience the health effects of economic and social change (Waldron et al. 1982; McGarvey et al. 1989; Bindon 2007; Snodgrass et al. 2007). For example, the main cardiovascular risk factor for native Siberians is high blood pressure, yet these populations display relatively favourable blood lipid levels (Leonard et al. 2005; Snodgrass et al. 2007). This contrasts with the Pima of North America and Aboriginal Australians who appear to be particularly susceptible to insulin resistance and T2D (O’Dea 1991; Resnick et al. 2003). At present, the extent to which genetic and lifestyle factors interact to shape regional variation in chronic disease patterns remains unclear, yet links between health risk and metabolic patterns suggests that there may be an adaptive component to this variation (Snodgrass et al. 2008). A major challenge facing researchers is to connect specific cultural and lifestyle changes to health outcomes and to explain intra- and inter-population variation in health profiles. These findings again highlight the complex, inter-related pathways-including genetics, behaviour, healthcare, environmental resources and demographics-by which changes in economic, social and cultural systems can impact individual health and lead to significant differences among populations in chronic disease prevalence.

One final issue related to MI and health is the paucity of research focused on the consequences of dietary and lifestyle change for indigenous South American groups. The few studies that do exist document variable effects of greater MI on child growth (Foster et al. 2005; Blackwell et al. 2009; Piperata et al. 2011), as well as higher rates of cardiovascular and metabolic risk factors such as obesity and elevated plasma glucose (Pavan et al. 1999; Tavares et al. 2003; Lindegärde et al. 2004, 2006; Lu 2007; Valeggia et al. 2010). Further, previous research among native South Americans has generally focused on single markers of cardiovascular or metabolic health (e.g. blood pressure, total cholesterol, fasting glucose or obesity), which gives an incomplete and narrow picture of the health implications of culture change in these populations.

The present study broadens the literature on these issues by examining MI and a variety of markers of cardiovascular and metabolic health among Shuar, an indigenous population from Amazonian Ecuador. Shuar currently experience a wide range of MI both within and between communities. In general, however, communities in the Upano Valley (UV) have greater access to roads and towns, which increases access to wage labour as well as markets for sale and purchase of food. In contrast, villages east of the Cutucú mountain range have limited road access, and most people in this region remain largely dependent on horticulture, fishing and hunting for daily subsistence. Thus, while Shuar populations are closely genetically related and share a common recent culture, their variation in market access and integration into a market economy provides an excellent opportunity to examine the effects of rapid economic development on individual health. The present study has the following three objectives:

- Objective One: Evaluate the health of indigenous Ecuadorian Shuar to characterize patterns of cardiovascular and metabolic risk. We hypothesize that Shuar will display relatively favourable cardiovascular and metabolic health profiles based on current clinical guidelines from the US and other industrialized nations. This expectation is based on the overall low degree of MI among Shuar and their continued reliance (although to varying degrees) on a subsistence lifestyle.

- Objective Two: Compare cardiovascular and metabolic health of Shuar from the UV and Cross-Cutucú (CC) regions. We hypothesize that UV Shuar will demonstrate less favourable cardiovascular and metabolic health profiles (assessed based on fasting glucose, lipids and blood pressure) as a result of increased exposure to and engagement with the cultural and economic systems associated with Western societies.

- Objective Three: Examine how specific factors related to MI, including dietary and lifestyle measures, are associated with different cardiovascular and metabolic health outcomes. We hypothesize that increased consumption of market-based foods (e.g. soda, rice and processed carbohydrates), ownership of more consumer goods and residence in a household with modern features indicate greater participation in the market economy and will be associated with poorer cardiovascular and metabolic health. 


\section{MATERIALS AND METHODS}

\section{Study populations}

This study was conducted among the indigenous Shuar of lowland Amazonian Ecuador in the province of MoronaSantiago (Figure 1). Since 2005, the Shuar Health and Life History Project has been conducting fieldwork in Ecuador as a collaborative research effort that involves faculty and graduate students from several universities as well as local Ecuadorian organizations, including the Federación Interprovincial de Centros Shuar (FICSH), the Ecuadorian health ministry and community members. A primary objective of the project is to investigate how cultural and economic changes associated with MI affect individual- and community-level health outcomes. One of the current authors (Sugiyama) has worked with Shuar and closely-related Achuar and Shiwiar since 1993, providing much of our ethnographic knowledge about traditional life as well as initial insights into cultural changes occurring among the Shuar.

The Shuar occupy the southeastern neo-tropical forest of Ecuador and the northeastern region of Peru. Traditionally, Shuar lived in scattered households across the Paute and Upano River Valleys, between the eastern Andean foothills and the Cordillera de Cutucú. Warfare and feuding were endemic, while traditional interpersonal alliances allowed Shuar to coalesce in order to expel Inca and later Spanish invaders; these conditions have facilitated Shuar resistance to colonial expansion to the present day (Karsten 1935; Stirling 1938; Harner 1984; Descola 1994, 1996; Rubenstein 2001). First direct contact between Shuar and non-Shuar (Colonos) was with Spaniards in 1549. Shuar later expelled the Spaniards from their territory in 1599 and permanent trade was not re-established until the 1890s. Through the renewed trade system, Shuar gained access to shotguns and expanded eastward from the UV and Paute river drainage across the Cutucú mountain range, which remains the main geographic barrier limiting economic development in the eastern lowlands. Missionization started in the 1940s, but larger-scale colonization did not begin until the 1950s. With the formation of FICSH in the 1960s to protect Shuar interests, most households began clustering in centros (i.e. communities or villages) in response to various political exigencies. At present, the Ecuadorian Shuar are a rapidly growing population of $\sim 60000-110000$ persons living in 668 communities (Rubenstein 2002; CODENPE 2012). With very few exceptions, Shuar living in communities remain a natural fertility population with limited contraception-use: average age at menarche $\sim 13$ years, first parturition 17.5 and average lifetime live births among postmenopausal women 8.4 (Madimenos et al. 2012).

Geographically, the UV is characterized by montane neotropical forest, while the CC is characterized by forest ranging from montane to lowland floodplain. The UV

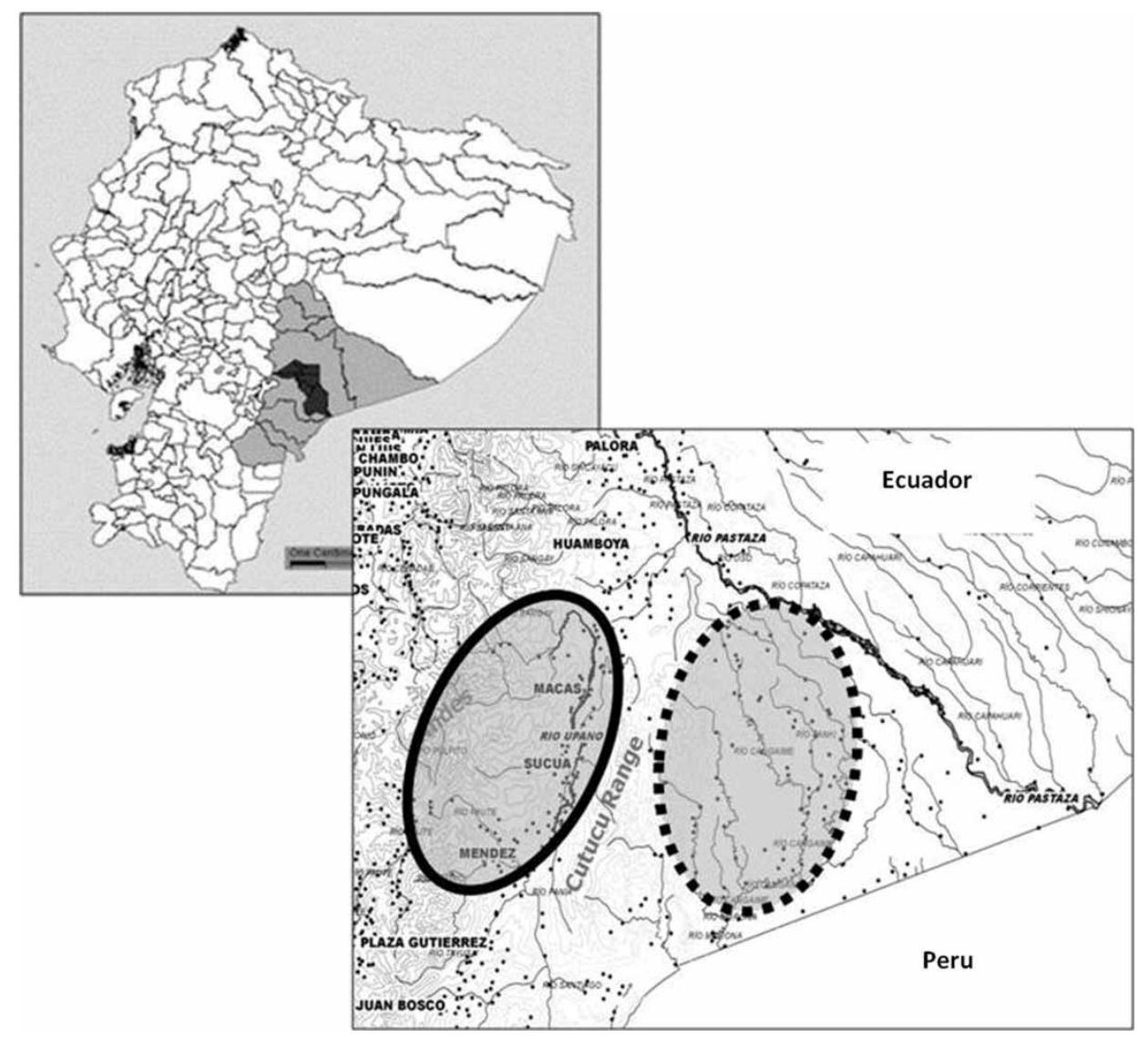

Figure 1. Map of Ecuador with inset showing details of the study area, including the Upano River Valley (bold oval) and Cross-Cutucú (dashed oval) regions. 
region experiences less rainfall and temperature variation across the year compared to CC; for example, average temperature in the UV ranges from $16-20^{\circ} \mathrm{C}$, while temperature in the $\mathrm{CC}$ region averages between $24-38^{\circ} \mathrm{C}$ (Madimenos et al. 2011).

Although some Shuar live fully market-integrated lifestyles in towns, diet within Shuar communities remains based primarily on subsistence horticulture (Harner 1984; Descola 1996). Each Shuar household typically has two or three gardens at different stages of production or a single large garden, with intercropping and staggered planting seasons. Gardens provide the primary source of carbohydrates, contributing $\sim 65 \%$ of dietary calories. Staple foods include yucca and plantains, which are consumed daily. Other important crops include sweet potato, bananas, palm, maize, papaya, pineapple and sugar cane (Harner 1984). Hunting was traditionally practiced with blowguns, dogs and traps, but shotguns have been used for a hundred years. In some areas, collared peccary continues to be an important source of game, as well as paca, tapirs, armadillos and several monkey species (e.g. woolly, howler and capuchin) (ZapataRíos et al. 2009). Traditional fishing involved two kinds of fish poisons (barbasco or timiu), although nets and hooks/lines are now also used. While no direct observational data on hunting and fishing productivity in the UV are currently available, ethnographic observations, interviews and food frequency data indicate that hunting and fishing near UV communities has declined, while these foraging practices, particularly fishing, remain productive and important subsistence regimes in the CC area.

In UV communities, most Shuar now purchase a range of market items and engage in some market-oriented agropastoralism or wage labour. For example, in a 2005 survey, $19 \%$ of households in this region sold timber in the past year, 30\% sold crops of some kind and 38\% either owned a cow or raised one owned by another person (McSweeney and Jokisch 2007). A few Shuar earn salaries as government employees (e.g. school teachers or nurses), but most wage labour is based on day-work, in which both male and female UV Shuar participate. Further, most UV Shuar currently live within walking distance of roads, reside in large communities and have divided land into individually-owned plots (Rubenstein 2001; Lu 2007; Madimenos et al. 2011). The UV sample in the current study includes rural communities located $\sim 45$ minutes outside of the town of Sucúa by paved and dirt road. These villages offer water lines coming from fresh-water springs, electricity for those who can afford it and regular access to small stores and markets in town and the regional centre.

In contrast, the CC communities are located $\sim 9$ hours by bus and an additional 6-12 hours by motorized canoe from the regional centre (at the time of data collection). Individuals in these communities have no direct road access and less reliable travel infrastructure, primarily due to frequent landslides and limits on canoe travel during high or very low river stages. As a result, CC villages lack efficient market access; thus, subsistence remains based on fishing, hunting and horticulture, with limited agricultural, cattle or timber sales (Blackwell et al. 2009; Zapata-Ríos et al. 2009; Madimenos et al. 2011).

\section{Participants}

This study includes a total of 348 Shuar with data collected over six field seasons [Summer $2007(n=34)$, Summer $2008(n=71)$, Winter $2009(n=24)$, Summer 2009 $(n=49)$, Winter $2010 \quad(n=2)$ and Summer 2010 $(n=168)]$. Data come from five UV (99 males, 155 females) and three CC communities (37 males, 57 females). Only adults ( $\geq 15$ years) were included and participants ranged in age from 15-90 years. Ages were determined by birthdates on government identification cards and the collection of extensive genealogical information, which included details about siblings and offspring, in order of birth. Overlapping genealogies were collected from multiple informants to cross-check information (Blackwell et al. 2010). Pregnant women were not included in the study.

All individuals were measured and interviewed at least once, while some individuals were examined across multiple field seasons. In cases where individuals had repeated measurements, the most recently collected health, lifestyle and diet data from a single field season was used for analysis. For each participant, lifestyle and diet data were collected concurrently with the cardiovascular and metabolic health measures. Most individuals came from separate households (348 individuals from 299 households).

The study was approved by village leaders, $\mathrm{FISCH}$ and the Office for the Protection of Human Subjects at the University of Oregon. Informed verbal consent was obtained from all participants.

\section{Anthropometric measurements}

Anthropometric measures were collected using established procedures (Lohman et al. 1988). One researcher was assigned to collect all of the measurements using a given technique during each field season and attempts were made to use the same researcher across multiple seasons. Training sessions were conducted prior to each field season to minimize inter-observer error. Stature was recorded to the nearest $1.0 \mathrm{~mm}$ using a field stadiometer (Seca Corporation, Hanover, MD). Body weight was measured to the nearest $0.1 \mathrm{~kg}$ (with participants in light clothing) using a Tanita BF558 electronic scale (Tanita Corporation, Tokyo, Japan). Three circumferences (waist, mid-arm and hip) were recorded. Stature, weight and all body circumferences were determined by a single measurement. Body fat was estimated according to the sum of four skin-folds (triceps, biceps, subscapular and superiliac) using sex- and agespecific equations (Durnin and Womersley 1974). Skin-fold measurements were repeated 3-times without clothing and estimated to the nearest $0.5 \mathrm{~mm}$ with Lange skin-fold calipers (Beta Technology, Santa Cruz, CA).

\section{Health measures}

To evaluate cardiovascular health, a finger prick with a sterile, disposable lancet was used to obtain $35 \mu \mathrm{L}$ of whole capillary blood, which allowed for measurement of total 
cholesterol (TC), HDL cholesterol, LDL cholesterol and triglycerides. Fasting glucose concentration was measured from $15 \mu \mathrm{L}$ of whole capillary blood, typically obtained from the same finger prick. Both samples were assessed using a CardioChek PA clinical system and PTS panels (Polymer Technology Systems, Indianapolis, IN). This instrument provides immediate measurements of glucose and lipid values and meets US standard clinical guidelines for accuracy and precision. All measures were obtained from participants after a 12-hour fast. The CardioChek PA classifies individuals with triglycerides below $50 \mathrm{mg} / \mathrm{dL}$ as 'low' with no numeric value provided; in these cases, LDL cholesterol cannot be calculated since LDL values are estimated using the Friedewald Equation (LDL $=$ TC - HDL - TG/5).

As recommended by the US National Cholesterol Education Program (NCEP 2001), desirable lipid levels are: TC $<240 \mathrm{mg} / \mathrm{dL} ; \mathrm{HDL} \geq 40 \mathrm{mg} / \mathrm{dL} ; \mathrm{LDL}<160 \mathrm{mg} / \mathrm{dL}$ and triglycerides $<150 \mathrm{mg} / \mathrm{dL}$. Fasting glucose levels were classified based on American Diabetes Association (ADA) guidelines as normal $(<100 \mathrm{mg} / \mathrm{dL})$, impaired fasting glucose $(100-126 \mathrm{mg} / \mathrm{dL})$ and diabetes $(\geq 126 \mathrm{mg} / \mathrm{dL})$ (Genuth et al. 2003).

Arterial blood pressure was measured as systolic blood pressure (SBP; mmHg) over diastolic blood pressure (DBP; $\mathrm{mmHg}$ ). All participants sat in a relaxed position while a trained observer collected a single measurement with an automatic Lifesource UA-767 Plus blood pressure monitor (A\&D Medical, San Jose, CA). Following guidelines from Kaplan (2002), SBP at or above $140 \mathrm{mmHg}$ and/or DBP at or above $90 \mathrm{mmHg}$ were classified as hypertensive, values between $120 / 80$ and $139 / 89 \mathrm{mmHg}$ were prehypertensive and levels at or below $120 / 80 \mathrm{mmHg}$ were normotensive (WHO/ISH 2003).

\section{Lifestyle factors}

Structured interviews were conducted to collect basic demographic and lifestyle information. All instruments were administered in Spanish, which most Shuar speak fluently. A bilingual assistant translated for those participants not fluent in Spanish. All participants were asked a series of questions from a modified version of the Material Style of Life (SOL) Index (Bindon et al. 1997; Leonard et al. 2002). The SOL is simply a list of market items, and SOL scores are the sum of the number of index items a household owns. For this study, we constructed two scales, referred to as Traditional Style of Life (T-SOL) and Market-Integrated Style of Life (M-SOL), to assess not only market good ownership but ownership of goods involved in traditional subsistence activities.

The selection of items in the Shuar SOL was based on several years of ethnographic observations by one author (Sugiyama) and initial interviews conducted with extensive lists of items that were shortened after pilot testing (unpublished data). Items were selected that were not so common as to lack variation between households (e.g. pots and machetes are owned by all households so were not included in the final scale), but not so rare as to be unique to individual households. We also selected items representing a continuum of investment in the traditional economy or involvement in market trade. For example, chainsaws require a large initial investment and the continual purchase of gasoline. The final T-SOL scale contained six items reflecting investment in a foraging lifestyle (fishing hook/line, hunting dogs, blowgun, firearm, fishing net, canoe), while the M-SOL scale included 12 items reflecting investment in a market economy (radio, propane stove, mobile phone, TV, chainsaw, bicycle, refrigerator, computer, outboard motor, motorcycle, car, truck). Individual scores were calculated as the fraction of list items owned (range $0-1$ ).

Six household measures were also incorporated as indices of household permanence, access to infrastructure (water and electricity), market participation and pathogen risk. These included [in order of increasing market integration (with values and scores in parentheses)]: floor (0: dirt, 1: palmwood, 2: milled lumber, 3: concrete), wall (0: palmwood, 1: milled lumber, 2: cinder block), latrine type ( 0 : none, 1 : pit toilet, 2 : outhouse with water, 3 : indoor toilet), water source (0: river/stream/spring pond, 1 : well or outdoor pipe, 2: indoor pipe), electricity (0: none, 1: lights, 2: outlet) and number of rooms in house. A Household Style of Life (H-SOL) value for each individual was computed based on a summation of the scores shown.

In general, high T-SOL values indicate greater participation in subsistence activities, while high M-SOL and $\mathrm{H}-\mathrm{SOL}$ values indicate greater participation in market activities. However, it is important to note that, although across households the M-SOL and H-SOL are positively correlated with each other and negatively correlated with the T-SOL, individual households could be high on all scales, low on all or any combination. For this reason, separate analyses based on the T-SOL, M-SOL and H-SOL scores were conducted.

\section{Dietary factors}

In accordance with standard field techniques used to measure dietary composition (Rimm et al. 1992; Rutishauser and Black 2002), a Food Frequency Questionnaire (FFQ) was administered via structured interviews to collect information about common food items and typical fooduse patterns among Shuar. The FFQ was designed to efficiently assess variation in diet between individuals rather than to provide exact caloric or nutritional estimates. During pilot work, 24-hour food recalls were collected from several dozen individuals (unpublished data). Foods listed in these recalls and/or known from extensive ethnographic work were combined into a food frequency questionnaire, which included 19 common food items or food categories (e.g. rather than ask about individual foods, items such as chicken, duck and turkey were combined into a single poultry category, as were sugary drinks, fruits and so forth) (Table I). Participants were asked how often a specific category or type of food was consumed and could respond with reference to the unit of time preferred (per week, per month or per year). To account for seasonality, individuals were asked whether their patterns were typical for the year 
Table I. Factor loadings of the 19 food frequency items on five promax-rotated principal components for all Shuar participants.

\begin{tabular}{|c|c|c|c|c|c|}
\hline & \multicolumn{5}{|c|}{ Components } \\
\hline & $\begin{array}{c}\text { Factor 1: } \\
\text { Market Foods }\end{array}$ & $\begin{array}{c}\text { Factor 2: } \\
\text { Fruits, Vegetables \& Eggs }\end{array}$ & $\begin{array}{c}\text { Factor 3: } \\
\text { Hunted Game \& Chicken }\end{array}$ & $\begin{array}{c}\text { Factor } 4: \\
\text { Fish \& Beef }\end{array}$ & $\begin{array}{c}\text { Factor 5: } \\
\text { Market Carbohydrates }\end{array}$ \\
\hline Soda & 0.74 & & & & \\
\hline Cookies \& Sweets & 0.71 & & & & \\
\hline Potato Chips & 0.66 & & & & \\
\hline Rice & 0.54 & & & & \\
\hline Butter \& Oil & 0.48 & & & & \\
\hline Bread & 0.47 & & & & \\
\hline Dairy Products & 0.41 & & & & \\
\hline Fruits & & 0.73 & & & \\
\hline Local Plant Greens & & 0.72 & & & \\
\hline Vegetables \& Legumes & & 0.66 & & & \\
\hline Eggs & & 0.38 & & & \\
\hline Hunted Game & & & 0.80 & & \\
\hline Hunted Birds & & & 0.77 & & \\
\hline Chicken & & & 0.42 & & \\
\hline Fish \& Shellfish & & & & 0.84 & \\
\hline Beef & & & & 0.67 & \\
\hline Pasta & & & & & 0.69 \\
\hline Local Potatoes & & & & & -0.60 \\
\hline Yucca \& Plantains & & & & & -0.55 \\
\hline
\end{tabular}

or if their consumption pattern varied seasonally or based on occasional cash flow. Responses were then standardized as consumption frequency per year (i.e. an item consumed daily was counted as 365 times per year).

\section{Statistical procedures}

Reduction of dietary factors. Due to the large number of dietary variables, FFQ data were reduced to a few manageable factors capturing the primary dimensions of variation. First, the internal consistency of the FFQ was calculated to determine the degree of inter-correlation between the food items, which is a standard psychometric procedure used prior to a principal components analysis. As indicated by Cronbach's coefficient alpha, the internal consistency of the FFQ was relatively high ( $\alpha=0.72)$. Thus, all 19 items were retained for assessment and were evaluated with principal components analysis in order to examine the patterns of correlations between food items and to reduce dietary variables into manageable factors for multivariate statistical tests (Tabachnick and Fidell 2012). Further, the 19 items in the FFQ were rotated using an oblique promax procedure to maximize the factor loadings and improve the interpretation of results. Based on the scree test, five components with eigenvalues greater than one were identified. Table I presents the factor structure of the rotated solution, which cumulatively accounted for $49.1 \%$ of the item variance. Market products such as rice, bread and soda loaded positively on the first component, which included seven items and was classified as the Market Food Component (Factor 1). Local plant greens, fruits, vegetables/legumes and eggs loaded onto the second component, which was identified as the Fruits, Vegetables and Eggs Component (Factor 2). The third component included chicken and two items related to hunted game (hunted game and hunted birds) and was described as the Hunted Game and Chicken Component (Factor 3). Two items, fish/shellfish and beef, loaded onto the fourth component, which was defined as the Fish and Beef Component (Factor 4). Market food products high in refined carbohydrates, such as pasta, clustered onto the fifth component, while local carbohydrate-based products, such as potatoes, yucca and plantains, were negatively associated with this dimension; this construct was named the Market Carbohydrates Component (Factor 5). For all subsequent analyses, the five food components were used as indicators of dietary patterns. Positive FFQ values indicated greater consumption of a specific food category, whereas negative FFQ values specified lower consumption. All FFQ analyses were conducted with sexes combined.

Hypothesis testing. Prior to analysis, all variables were examined for accuracy of meeting standard parametric assumptions. Some variables were slightly skewed so tests were conducted with both $\log _{10}$-transformed and nontransformed data. Using transformed values did not significantly change results; thus, tests with nontransformed values are reported since they are more interpretable. We excluded one 32-year-old woman from a CC community who had a fasting glucose level of 299 and was identified as a statistical outlier. Given her age and the extreme nature of her health status, we suspect her condition was either untreated type I diabetes or perhaps a secondary complication of an undiagnosed medical ailment.

- Objective One: Descriptive statistics were calculated to characterize patterns of cardiovascular and metabolic health among Shuar. Independent-samples $t$-tests (twotailed) were used to evaluate differences between males and females from the same subject population (e.g. Shuar males from the UV vs Shuar females from the UV) for age, the seven health markers (glucose, TC, HDL, LDL, triglycerides, SBP and DBP) and anthropometrics (BMI and percentage body fat). 
- Objective Two: Two-way analysis of covariance (ANCOVA) tests, with age and BMI as covariates, were conducted to compare the cardiovascular and metabolic health of male and female Shuar from the UV and CC regions. This procedure was used to examine the main effects and interactions of sex and population, while controlling for the effects of age and BMI on the cardiovascular and metabolic measures. To verify that the relationship between the covariates and dependent variables did not differ significantly as a function of sex and population, the homogeneity-of-slopes assumption was evaluated; six of the seven health markers (glucose, TC, HDL, LDL, SBP, DBP) did not violate this assumption. For triglycerides, BMI as a covariate significantly interacted with the main effect of sex, indicating that BMI varied between males and females and could not be used as a covariate in the ANCOVA models. The following results for triglycerides were evaluated in consideration of this homogeneity-of-slopes violation. All means and standard errors are reported after adjusting for the covariates (age and BMI). For ANCOVA analyses with a significant interaction between sex and population, follow-up simple main effect tests were conducted to examine the differences in means among UV and CC males and females.

- Objective Three: Multivariate statistical techniques were used to examine the relationship between dietary and lifestyle measures and cardiovascular and metabolic health outcomes. Pair-wise partial correlations (controlling for age, sex and BMI) were computed among the seven health markers (glucose, TC, HDL, LDL, triglycerides, SBP, DBP), the five food factors (Market Foods; Fruits, Vegetables and Eggs; Hunted Game and Chicken; Fish and Beef; Market Carbohydrates) and the three SOL values (H-SOL, T-SOL and M-SOL). Multiple regression tests with the seven health markers as dependent variables were used to estimate the relative association of age, sex, BMI, the five food factors and the three SOL values to the cardiovascular and metabolic measures. All statistical analyses were conducted with SPSS version 18.0 (SPSS Inc., Chicago, IL). Comparisons were regarded as significant at $p<0.05$, unless indicated otherwise.

\section{RESULTS}

\section{Objective One: Cardiovascular and metabolic health profiles among Shuar}

Descriptive statistics for age, anthropometry and health measures are presented in Table II for male and female CC Shuar and UV Shuar. With reference to current international guidelines (NCEP 2001; Kaplan 2002; WHO 2002; Genuth et al. 2003), the mean values for all health measures for males and females from all groups were in the clinicallynormal range.

Independent samples $t$-tests identified significant differences between CC males and females for glucose $(t(79)=-2.01, p=0.048)$ and percentage body fat $(t(46)=-10.30, p<0.001)$, with females demonstrating higher levels for both markers (Table II). For UV Shuar, females had higher levels of TC $(t(225)=-3.45$, $p=0.001)$, HDL $(t(225)=-2.59, p=0.010)$, LDL $(t(196)=-5.06, p<0.001)$ and percentage body fat $(t(245)=-20.75, p<0.001)$. In contrast, UV males had higher levels of triglycerides $(t(223)=2.15, p=0.032)$, SBP $(t(212)=4.94, p<0.001)$ and DBP $(t(212)=3.29$, $p=0.001)$.

\section{Objective Two: Comparing health measures between Cross- Cutucú Shuar and Upano Valley Shuar}

A series of two-way analysis of covariance (ANCOVA) tests, with age and $\mathrm{BMI}$ as covariates, were conducted to compare the cardiovascular and metabolic health of male and female Shuar from the UV and CC regions. The significant test results for the lipid measures (TC, HDL, LDL, triglycerides) and the metabolic and blood pressure markers (glucose, SBP, DBP) are presented in Tables III and IV, respectively. The ANCOVA for TC identified a significant difference between males $(M=157.34, \mathrm{SE}=4.01)$ and females $(M=171.17, \quad \mathrm{SE}=3.35)$, as well as between $\mathrm{UV}$

Table II. Descriptive statistics for cardiovascular, metabolic and anthropometric health markers. ${ }^{\text {ab }}$

\begin{tabular}{|c|c|c|c|c|c|c|c|c|}
\hline \multirow[b]{3}{*}{ Measure } & \multicolumn{4}{|c|}{ Cross-Cutucú Shuar } & \multicolumn{4}{|c|}{ Upano Valley Shuar } \\
\hline & \multicolumn{2}{|r|}{ Males } & \multicolumn{2}{|r|}{ Females } & \multicolumn{2}{|r|}{ Males } & \multicolumn{2}{|r|}{ Females } \\
\hline & $n$ & Mean (SD) & $n$ & Mean $(\mathrm{SD})$ & $n$ & Mean (SD) & $n$ & Mean (SD) \\
\hline Age (years) & 37 & $39.7(15.1)$ & 57 & $36.2(14.8)$ & 99 & $40.2 \star * \star(15.7)$ & 155 & $35.2(15.4)$ \\
\hline Glucose $(\mathrm{mg} / \mathrm{dL})$ & 32 & $73.6 * * *(13.2)$ & 49 & $82.1(21.2)$ & 72 & $77.0(11.3)$ & 117 & $78.1(11.7)$ \\
\hline Total cholesterol (mg/dL) & 35 & $150.7(34.9)$ & 53 & $154.7(36.7)$ & 85 & $167.0 *(35.6)$ & 142 & $186.4(44.0)$ \\
\hline $\mathrm{HDL}(\mathrm{mg} / \mathrm{dL})$ & 35 & $38.2(9.4)$ & 53 & $42.9(14.4)$ & 85 & $52.1 * \star(14.0)$ & 142 & $57.1(14.1)$ \\
\hline $\mathrm{LDL}(\mathrm{mg} / \mathrm{dL})$ & 24 & $90.1(25.3)$ & 43 & $88.6(26.3)$ & 73 & $85.2 *(24.4)$ & 125 & $106.8(31.3)$ \\
\hline Triglycerides $^{c}(\mathrm{mg} / \mathrm{dL})$ & 35 & $142.5(103.7) /[117.0]$ & 52 & $118.8(71.5) /[107.0]$ & 83 & $139.3^{\star * *}(81.0) /[119.0]$ & 142 & $118.4(63.4) /[103.0]$ \\
\hline Blood pressure-Systolic (mmHg) & 13 & $115.4(13.6)$ & 19 & $110.3(9.7)$ & 84 & $121.4^{*}(15.9)$ & 130 & $110.2(16.6)$ \\
\hline Blood pressure-Diastolic $(\mathrm{mmHg})$ & 13 & $77.0(7.5)$ & 19 & $76.4(9.4)$ & 84 & $75.7 *(8.2)$ & 130 & $71.4(9.7)$ \\
\hline BMI $\left(\mathrm{kg} / \mathrm{m}^{2}\right)$ & 36 & $24.8(3.1)$ & 50 & $24.2(2.5)$ & 99 & $25.2(2.6)$ & 155 & $24.8(3.1)$ \\
\hline Body fat $(\%)$ & 19 & $14.7 *(4.8)$ & 29 & $28.8(4.5)$ & 97 & $16.4^{*}(4.0)$ & 150 & $27.7(4.3)$ \\
\hline
\end{tabular}

${ }^{\mathrm{a}}$ All values are presented as means and standard deviations, unless noted otherwise.; ${ }^{\mathrm{b}}$ Differences between males and females from the same subject population (e.g. Shuar males from the Upano River Valley vs Shuar females from the Upano River Valley) are statistically significant at: ${ }^{*} p \leq 0.001 ; * \star p<0.01$; ${ }^{* * *} p<0.05$. 'Mean and SD only includes a sub-set of cases where triglycerides were at or above $50 \mathrm{mg} / \mathrm{dL}$ (cases $<50 \mathrm{mg} / \mathrm{dL}$ were classified as 'low', only with no numeric value provided by the CardioChek PA); medians for each sample are presented in brackets. 
Table III. Two-way analysis of covariance tests (controlling for age and BMI) comparing Upano River Valley and Cross-Cutucú male and female Shuar on lipid health measures. ${ }^{\text {a }}$

\begin{tabular}{|c|c|c|}
\hline Variable & $F$ & $p$ \\
\hline \multicolumn{3}{|c|}{ Total cholesterol $(\mathrm{mg} / \mathrm{dL})$} \\
\hline Age & 11.097 & $0.001 *$ \\
\hline BMI & 1.742 & 0.188 \\
\hline Sex & 6.924 & $0.009 * *$ \\
\hline Population & 20.719 & $0.000^{*}$ \\
\hline Sex $\times$ Population & 3.027 & 0.083 \\
\hline \multicolumn{3}{|l|}{$\mathrm{HDL}(\mathrm{mg} / \mathrm{dL})$} \\
\hline Age & 8.651 & $0.004^{\star \star}$ \\
\hline BMI & 5.481 & $0.020 * * *$ \\
\hline Sex & 9.110 & $0.003^{\star *}$ \\
\hline Population & 59.981 & $0.000^{*}$ \\
\hline Sex $\times$ Population & 0.008 & 0.928 \\
\hline \multicolumn{3}{|l|}{ LDL (mg/dL) } \\
\hline Age & 3.554 & 0.061 \\
\hline BMI & 0.288 & 0.592 \\
\hline Sex & 5.174 & $0.024 * * *$ \\
\hline Population & 2.518 & 0.114 \\
\hline Sex $\times$ Population & 8.838 & $0.003^{* *}$ \\
\hline \multicolumn{3}{|l|}{ Triglycerides (mg/dL) } \\
\hline Age & 3.133 & 0.078 \\
\hline BMI & 29.094 & $0.000^{*}$ \\
\hline Sex & 2.618 & 0.107 \\
\hline Population & 0.053 & 0.818 \\
\hline Sex $\times$ Population & 0.005 & 0.944 \\
\hline
\end{tabular}

$(M=176.10, \mathrm{SE}=2.70)$ and $\mathrm{CC}$ Shuar $(M=152.42$, SE = 4.45). Similarly, the results for HDL cholesterol revealed that females $(M=50.41, \mathrm{SE}=1.15)$ had higher levels than males $(M=44.96, \mathrm{SE}=1.38)$ and UV Shuar $(M=54.61$, SE $=0.93)$ had higher levels than CC Shuar $(M=40.77, \mathrm{SE}=1.53)$. For LDL cholesterol, females $(M=97.47, \mathrm{SE}=2.64)$ had higher levels than males $(M=85.55, \mathrm{SE}=3.43)$. There was also a significant interaction between sex and population for LDL cholesterol as a result of UV females $(M=107.25, \mathrm{SE}=2.55)$ having significantly higher levels than both UV males $(M=84.57$, SE $=3.34), t(261)=3.64, p<0.001$, and CC females $(M=87.70, \quad \mathrm{SE}=4.60), \quad t(261)=5.19, \quad p<0.001$ (Figure 2). For glucose, females $(M=81.60, \mathrm{SE}=1.21)$ had higher levels than males $(M=74.80, \mathrm{SE}=1.46)$. The interaction between sex and population for glucose was also significant, in which CC females $(M=84.81, \mathrm{SE}=2.07)$ had higher levels than CC males $(M=73.25, \mathrm{SE}=2.43)$, $t(266)=2.65, p=0.008$, while UV males $(M=76.25$, SE $=1.61)$ and females $(M=78.38, \mathrm{SE}=1.26)$ did not differ significantly, $t(266)=0.523, p=0.602$ (Figure 3 ). The test for DBP indicated that CC Shuar $(M=77.90, \mathrm{SE}=4.60)$ had higher levels than UV Shuar, $(M=73.29, \mathrm{SE}=0.61)$. For triglycerides and SBP, both the main effects of sex and population were non-significant.

\section{Objective Three: Cardiovascular and metabolic health of Shuar in relation to dietary and lifestyle factors}

With the UV and CC Shuar populations combined, pair-wise partial correlations (controlling for age, sex and
BMI) were conducted among the seven health markers (glucose, TC, HDL, LDL, triglycerides, SBP and DBP), the five food factors (Market Foods [Factor 1]; Fruits, Vegetables and Eggs [Factor 2]; Hunted Game and Chicken [Factor 3]; Fish and Beef [Factor 4]; Market Carbohydrates [Factor 5]) and the three SOL values (H-SOL, T-SOL, M-SOL). These findings are presented in Table V. Results revealed positive correlations between the H-SOL scale and Market Foods, Fruits, Vegetables and Eggs, Fish and Beef and Market Carbohydrates. The M-SOL scale also positively correlated with Market Foods, Fruits, Vegetables and Eggs, Fish and Beef and Market Carbohydrates, while the T-SOL scale positively correlated with Hunted Game and Chicken and negatively correlated with Market Foods and Market Carbohydrates.

Results further identified positive correlations between TC and Hunted Game and Chicken and Fish and Beef. HDL cholesterol was positively correlated with Market Foods, Hunted Game and Chicken, Market Carbohydrates, H-SOL and M-SOL. Triglycerides positively correlated with Hunted Game and Chicken. Glucose, LDL cholesterol, SBP and DBP did not correlate significantly with the food factors and SOL values.

Multiple regression tests were used to estimate the relative contribution of dietary and lifestyle factors to variation in cardiovascular and metabolic health. The regression model for each health indicator included age, sex, BMI, the five food components (Market Foods; Fruits, Vegetables and Eggs; Hunted Game and Chicken; Fish and Beef; Market Carbohydrates) and the three SOL scales ( $\mathrm{H}-\mathrm{SOL}, \mathrm{T}-\mathrm{SOL}$ and $\mathrm{M}-\mathrm{SOL})$; these results are presented in Tables VI and VII. The full regression model accounted for a considerable amount of variation in TC, HDL, LDL, triglycerides, SBP and DBP. The proportion of variance explained in the regression model with glucose as the

Table IV. Two-way analysis of covariance tests (controlling for age and BMI) comparing Upano River Valley and Cross-Cutucú male and female Shuar on metabolic and blood pressure markers. ${ }^{\mathrm{a}}$ b

\begin{tabular}{|c|c|c|}
\hline Variable & $F$ & $p$ \\
\hline \multicolumn{3}{|l|}{ Glucose $(\mathrm{mg} / \mathrm{dL})$} \\
\hline Age & 8.324 & $0.004^{\star *}$ \\
\hline BMI & 1.112 & 0.293 \\
\hline Sex & 12.621 & $0.000^{\star}$ \\
\hline Population & 0.775 & 0.380 \\
\hline Sex $\times$ Population & 6.327 & $0.013 * * *$ \\
\hline \multicolumn{3}{|l|}{$\mathrm{SBP}(\mathrm{mmHg})$} \\
\hline Age & 51.194 & $0.000^{*}$ \\
\hline BMI & 3.383 & 0.067 \\
\hline Sex & 3.806 & 0.052 \\
\hline Population & 0.144 & 0.705 \\
\hline Sex $\times$ Population & 1.281 & 0.259 \\
\hline \multicolumn{3}{|l|}{$\mathrm{DBP}(\mathrm{mmHg})$} \\
\hline Age & 3.047 & 0.082 \\
\hline BMI & 31.592 & $0.000^{*}$ \\
\hline Sex & 2.660 & 0.104 \\
\hline Population & 7.464 & $0.007 * *$ \\
\hline Sex $\times$ Population & 0.251 & 0.617 \\
\hline
\end{tabular}




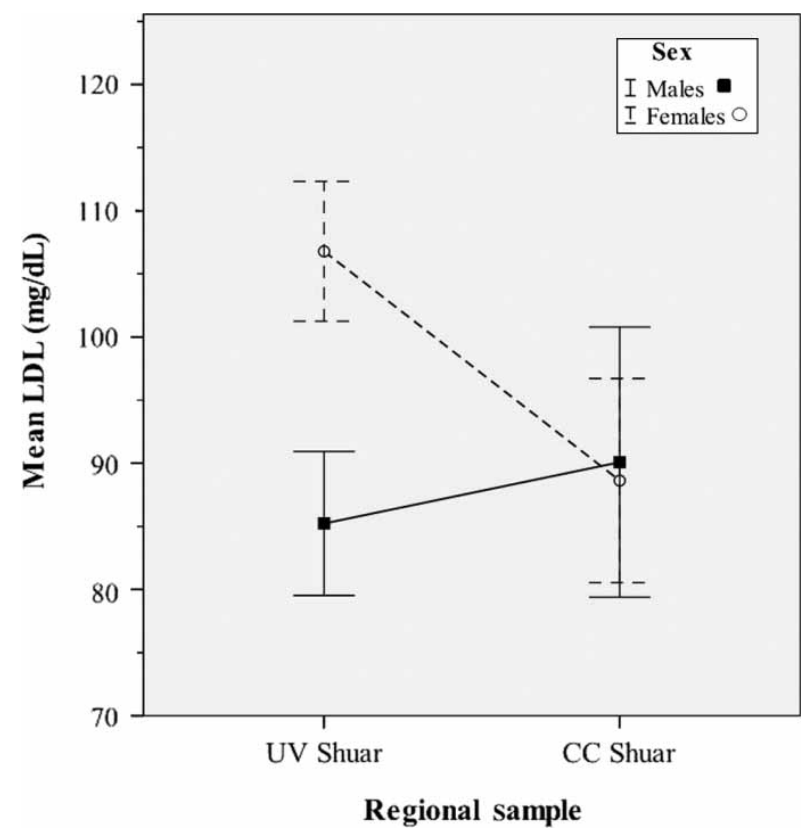

Figure 2. LDL (mg/dL) means (with 95\% confidence intervals) for male and female Shuar from the Upano River Valley and Cross-Cutucú regions.

dependent variable was not statistically significant but did show a positive trend. Age and sex were significant predictors of TC, HDL, LDL and SBP. BMI was a significant predictor of triglycerides and DBP. For the LDL cholesterol model, two food factors, Hunted Game and Chicken and Market Carbohydrates, were significant predictors. In the glucose regression model, the Fruits, Vegetables and Eggs food factor was a significant predictor, indicating that greater consumption of fruits, vegetables and eggs is associated with lower glucose levels (Table VII).

\section{DISCUSSION}

\section{Objective One: Cardiovascular and metabolic health profiles among Shuar}

As expected, the present study demonstrated that indigenous Shuar males and females have relatively favourable cardiovascular and metabolic health profiles according to established international guidelines (NCEP 2001; WHO 2002). Thus, while village-living Shuar are experiencing varying degrees of MI across their territory, the population in general maintains a cardiovascular and metabolic profile that contrasts markedly with most industrialized nations.

Nevertheless, our findings document considerable variation in cardiovascular health patterns within and between UV and CC regions. In part, this reflects the focus on multiple markers of chronic disease risk; however, it also suggests a relationship between MI and health that is heterogeneous and shaped by exposure to a range of factors associated with MI. For example, mean TC levels for males and females from the UV and CC regions were in the optimal range $(\leq 200 \mathrm{mg} / \mathrm{dL})$, yet SBP levels for UV males were elevated $(\geq 120 \mathrm{mmHg}$ ). The higher SBP levels of UV males may be a consequence of increased exposure to the chronic psychosocial stressors associated with involvement in a market economy, including economic competition and the emergence of new markers of social status commonly linked to Western material goods and lifestyles (Dressler et al. 1987; Dressler 1999; Bindon 2007); however, this issue remains speculative until other biomarker (e.g. cortisol) data on adult psychosocial stress profiles are collected from a larger sample of adults than currently available (Liebert et al. 2012).

This study also revealed important differences in cardiovascular and metabolic health between Shuar males and females. For example, females had significantly higher levels of TC, HDL, LDL and glucose than males. These results may reflect differences between Shuar males and females in their responses to dietary and lifestyle change, suggesting that there may be sex-specific physiological responses to the process of MI. Additional details about this finding are discussed below.

\section{Objective Two: Comparing health measures between Cross- Cutucú Shuar and Upano Valley Shuar}

Our results partially support the second hypothesis that UV Shuar would display less favourable cardiovascular and metabolic health profiles than CC Shuar. For example, Shuar from the UV had higher TC levels than CC Shuar; however, this finding appears to be the result of higher HDL cholesterol levels and, therefore, is not necessarily consistent with poorer cardiovascular health. Further, contrary to our prediction, Shuar from CC had higher DBP levels. Overall, this study shows many similarities between the two groups and contrasts with a number of previous studies that document rapid declines in cardiovascular and metabolic health with sociocultural and economic transitions

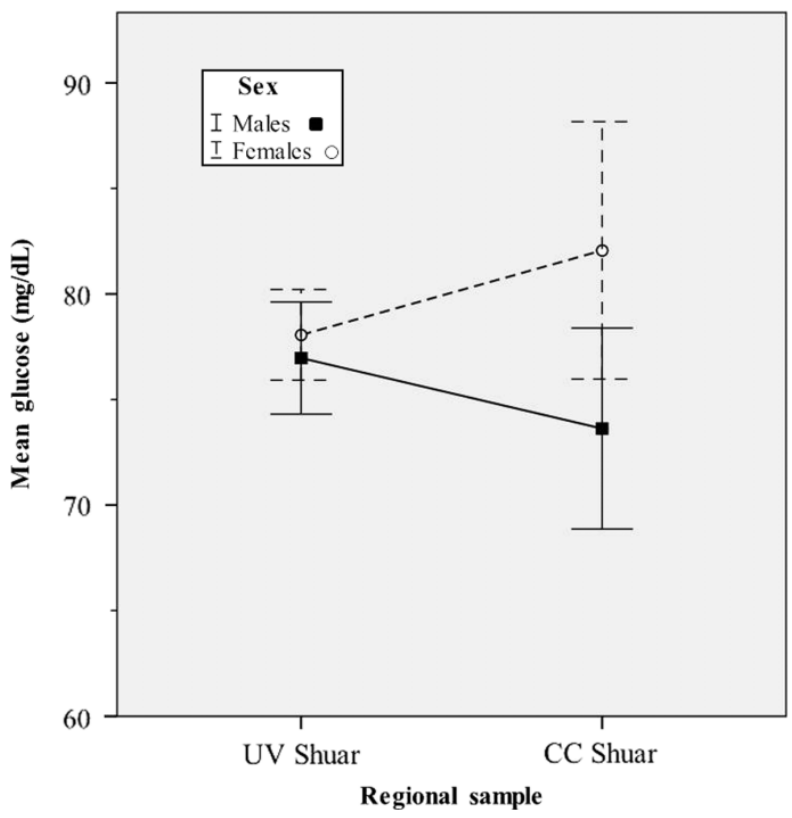

Figure 3. Glucose (mg/dL) means (with $95 \%$ confidence intervals) for male and female Shuar from the Upano River Valley and Cross-Cutucú regions. 
(Baker et al. 1986; Dressler et al. 1987; McGarvey et al. 1989; Huss-Ashmore et al. 1992; Gohdes 1995; Bindon 1995; Shephard and Rode 1996; Dressler 1999, 2004). There may be several reasons for a less pronounced decline in cardiovascular and metabolic health among Shuar in this sample. First, ethnographic observations and interview data suggest that the consumption of highly processed starches or fatty foods often associated with chronic diseases, such as diabetes and obesity, remain limited among village-dwelling Shuar. Specifically, our FFQ data demonstrates that the dietary staples in these communities remain a few traditional crops (e.g. plantains and yucca), regardless of level of MI. Plantains and bananas, in particular, may be protective against adverse cardiovascular health outcomes due to potassium content. Second, major changes in MI among Shuar are relatively recent; thus, the cumulative duration of exposure to cardiovascular and metabolic risks is likely lower than many other populations experiencing lifestyle change. Further, parasitism by helminth may help maintain normal blood lipid and BP levels (Vasunilashorn et al. 2010; Liebert et al. 2011). Indeed, helminth infections appear endemic, even in the UV (Blackwell et al. 2011; Cepon et al. 2012).

An alternative explanation is that our measures of MI may be limited in their ability to capture the critical components of MI that affect cardiovascular and metabolic health. Future work is needed to develop a more nuanced understanding of the relationship between culture change and cardiovascular and metabolic health.

One difficulty of interpreting population variation in the effects of MI is the potential for sex differences in health markers. An important finding in the present study is that Shuar females from the UV have significantly higher levels of LDL cholesterol compared to CC females as well as UV males. It is unclear what is responsible for this pattern, but it appears that Shuar females in market-integrated communities are more susceptible to some of the economic and cultural changes in this region, perhaps as a result of shifting dietary and activity patterns. Although speculative, our work among a UV community has demonstrated significantly lower activity levels among women compared to men (Madimenos et al. 2011), suggesting that decreasing physical activity among Shuar women may contribute to the worsening lipid profile. Further, UV Shuar females are progressively acquiring wage labour jobs in town, thereby increasing their exposure to processed, high fat market-food items such as cookies and sweets, which may potentially lead to elevated LDL cholesterol levels. Future research is needed to clarify these relationships.

The present study demonstrates that MI does not have a simple, homogenous, negative effect on health. Although many studies have found MI to be associated with rapid deterioration of cardiovascular and metabolic health, our results are similar to several other studies in their findings of mixed health outcomes (Berry et al. 1986; Godoy et al. 2005; Sorensen et al. 2005; Steffen et al. 2006). Whether MI has a positive or negative effect on health instead depends on local conditions and factors such as the character, intensity and duration of MI, the existing health and diet of the 
Table VI. Multiple regression models for prediction of lipid health measures among indigenous Shuar (sexes and populations combined). ${ }^{\mathrm{a}, \mathrm{b}, \mathrm{c}}$

\begin{tabular}{|c|c|c|c|c|}
\hline Variable & Coefficients (SE) & $\beta$ & $p$ & Model $r^{2}$ and $p$ \\
\hline Total cholesterol $(\mathrm{mg} / \mathrm{dL})$ & & & & $0.17 / 0.014^{* * *}$ \\
\hline Constant & $125.773(27.066)$ & & $<0.001$ & \\
\hline Age & $0.716(0.236)$ & 0.265 & 0.003 & \\
\hline Sex & $16.990(7.150)$ & 0.205 & 0.019 & \\
\hline BMI & $0.326(1.015)$ & 0.027 & 0.749 & \\
\hline Market Foods & $1.892(5.218)$ & 0.043 & 0.717 & \\
\hline Fruits, Vegetables and Eggs & $2.394(3.784)$ & 0.062 & 0.528 & \\
\hline Hunted Game and Chicken & $7.459(4.230)$ & 0.160 & 0.080 & \\
\hline Fish and Beef & $6.580(4.045)$ & 0.158 & 0.106 & \\
\hline Market Carbohydrates & $-3.135(4.358)$ & -0.073 & 0.473 & \\
\hline $\mathrm{H}-\mathrm{SOL}$ & $0.501(1.017)$ & 0.053 & 0.623 & \\
\hline T-SOL & $-9.500(8.913)$ & -0.098 & 0.289 & \\
\hline M-SOL & $10.100(18.955)$ & 0.051 & 0.595 & \\
\hline HDL cholesterol $(\mathrm{mg} / \mathrm{dL})$ & & & & $0.23 / 0.001^{*}$ \\
\hline Constant & $52.311(9.717)$ & & $<0.001$ & \\
\hline Age & $0.270(0.085)$ & 0.268 & 0.002 & \\
\hline Sex & $7.899(2.567)$ & 0.256 & 0.003 & \\
\hline BMI & $-0.698(0.364)$ & -0.158 & 0.058 & \\
\hline Market Foods & $0.571(1.873)$ & 0.035 & 0.761 & \\
\hline Fruits, Vegetables and Eggs & $-1.703(1.359)$ & -0.118 & 0.212 & \\
\hline Hunted Game and Chicken & $2.931(1.519)$ & 0.169 & 0.056 & \\
\hline Fish and Beef & $2.121(1.452)$ & 0.137 & 0.147 & \\
\hline Market Carbohydrates & $2.762(1.565)$ & 0.174 & 0.080 & \\
\hline $\mathrm{H}-\mathrm{SOL}$ & $0.623(0.365)$ & 0.176 & 0.091 & \\
\hline T-SOL & $-0.890(3.200)$ & -0.025 & 0.781 & \\
\hline M-SOL & $1.037(6.805)$ & 0.014 & 0.879 & \\
\hline LDL cholesterol $(\mathrm{mg} / \mathrm{dL})$ & & & & $0.24 / 0.002^{\star *}$ \\
\hline Constant & $97.022(19.388)$ & & $<0.001$ & \\
\hline Age & $0.394(0.171)$ & 0.213 & 0.023 & \\
\hline Sex & $16.452(5.234)$ & 0.289 & 0.002 & \\
\hline BMI & $-1.343(0.727)$ & -0.169 & 0.068 & \\
\hline Market Foods & $3.713(3.655)$ & 0.124 & 0.312 & \\
\hline Fruits, Vegetables and Eggs & $0.465(2.640)$ & 0.018 & 0.861 & \\
\hline Hunted Game and Chicken & $5.970(2.964)$ & 0.194 & 0.047 & \\
\hline Fish and Beef & $1.532(2.846)$ & 0.055 & 0.591 & \\
\hline Market Carbohydrates & $-9.632(3.061)$ & -0.335 & 0.002 & \\
\hline $\mathrm{H}-\mathrm{SOL}$ & $0.538(0.752)$ & 0.083 & 0.476 & \\
\hline T-SOL & $-6.600(6.312)$ & -0.103 & 0.298 & \\
\hline M-SOL & $23.452(13.128)$ & 0.177 & 0.077 & \\
\hline Triglycerides $(\mathrm{mg} / \mathrm{dL})$ & & & & $0.19 / 0.005^{\star *}$ \\
\hline Constant & $-39.541(38.924)$ & & 0.312 & \\
\hline Age & $0.415(0.340)$ & 0.106 & 0.225 & \\
\hline Sex & $-17.114(10.482)$ & -0.142 & 0.105 & \\
\hline BMI & $6.158(1.471)$ & 0.358 & $<0.001$ & \\
\hline Market Foods & $-6.413(7.579)$ & -0.100 & 0.399 & \\
\hline Fruits, Vegetables and Eggs & $6.156(5.458)$ & 0.110 & 0.262 & \\
\hline Hunted Game and Chicken & $0.409(6.112)$ & 0.006 & 0.947 & \\
\hline Fish and Beef & $6.197(5.836)$ & 0.103 & 0.290 & \\
\hline Market Carbohydrates & $3.790(6.331)$ & 0.061 & 0.550 & \\
\hline $\mathrm{H}-\mathrm{SOL}$ & $0.041(1.498)$ & 0.003 & 0.978 & \\
\hline T-SOL & $4.543(12.820)$ & 0.033 & 0.724 & \\
\hline M-SOL & $-38.268(24.437)$ & -0.133 & 0.166 & \\
\hline
\end{tabular}

${ }^{\mathrm{a}} \mathrm{TC}$, total cholesterol; HDL, HDL cholesterol; LDL, LDL cholesterol.;

${ }^{\mathrm{b}}$ Comparisons are statistically significant at: ${ }^{*} p \leq 0.001 ;{ }^{* *} p<0.01 ;{ }^{* *} p<0.05$.;

${ }^{\mathrm{c}}$ Sex: $0=$ Male, $1=$ Female.

population prior to MI, biological factors that shape susceptibility to health problems and cultural factors that influence behaviour. These findings emphasize the importance of using a range of health, dietary and lifestyle measures to capture the multi-faceted dimensions of MI and to understand how different populations adapt to both the adverse and beneficial effects of cultural and economic change.
Objective Three: Cardiovascular and metabolic health of Shuar in relation to dietary and lifestyle factors

To better understand how MI affects health-and how we can interpret population variation-the present study examined relationships among health measures, dietary patterns and lifestyle measures. Our results indicate that, among Shuar, degree of MI simultaneously affects lifestyle and diet, as Shuar who own more consumer products 
Table VII. Multiple regression models for prediction of metabolic and blood pressure markers among indigenous Shuar (sexes and populations combined). ${ }^{\mathrm{a}, \mathrm{b}, \mathrm{c}}$

\begin{tabular}{|c|c|c|c|c|}
\hline Variable & Coefficients (SE) & $\beta$ & $p$ & Model $r^{2}$ and $p$ \\
\hline Glucose (mg/dL) & & & & $0.15 / 0.085$ \\
\hline Constant & $64.486(9.022)$ & & $<0.001$ & \\
\hline Age & $0.123(0.076)$ & 0.155 & 0.111 & \\
\hline Sex & $3.276(2.336)$ & 0.137 & 0.164 & \\
\hline BMI & $0.329(0.316)$ & 0.096 & 0.300 & \\
\hline Market Foods & $2.549(1.657)$ & 0.195 & 0.127 & \\
\hline Fruits, Vegetables and Eggs & $-2.475(1.178)$ & -0.221 & 0.038 & \\
\hline Hunted Game and Chicken & $-0.556(1.526)$ & -0.036 & 0.716 & \\
\hline Fish and Beef & $2.453(1.405)$ & 0.187 & 0.084 & \\
\hline Market Carbohydrates & $-0.880(1.426)$ & -0.068 & 0.538 & \\
\hline $\mathrm{H}-\mathrm{SOL}$ & $-0.125(0.317)$ & -0.045 & 0.695 & \\
\hline T-SOL & $-0.137(2.977)$ & -0.005 & 0.963 & \\
\hline M-SOL & $-0.254(5.858)$ & -0.004 & 0.966 & \\
\hline SBP (mmHg) & & & & $0.32 /<0.001^{\star}$ \\
\hline Constant & $89.181(10.493)$ & & $<0.001$ & \\
\hline Age & $0.459(0.091)$ & 0.419 & $<0.001$ & \\
\hline Sex & $-8.581(2.758)$ & -0.259 & 0.002 & \\
\hline BMI & $0.699(0.377)$ & 0.149 & 0.066 & \\
\hline Market Foods & $1.150(1.830)$ & 0.069 & 0.531 & \\
\hline Fruits, Vegetables and Eggs & $-1.606(1.436)$ & -0.100 & 0.266 & \\
\hline Hunted Game and Chicken & $-0.380(1.555)$ & -0.036 & 0.807 & \\
\hline Fish and Beef & $1.627(1.540)$ & 0.187 & 0.293 & \\
\hline Market Carbohydrates & $1.002(1.543)$ & -0.068 & 0.517 & \\
\hline H-SOL & $-0.407(0.360)$ & -0.111 & 0.261 & \\
\hline T-SOL & $-4.134(3.572)$ & -0.100 & 0.249 & \\
\hline M-SOL & $-0.292(7.086)$ & -0.004 & 0.967 & \\
\hline$D B P(\mathrm{mmHg})$ & & & & $0.23 / 0.001 *$ \\
\hline Constant & $50.530(6.655)$ & & $<0.001$ & \\
\hline Age & $0.083(0.058)$ & 0.126 & 0.157 & \\
\hline Sex & $-2.466(1.750)$ & -0.125 & 0.161 & \\
\hline BMI & $0.954(0.239)$ & 0.340 & $<0.001$ & \\
\hline Market Foods & $1.983(1.161)$ & 0.198 & 0.090 & \\
\hline Fruits, Vegetables and Eggs & $-1.559(0.911)$ & -0.163 & 0.090 & \\
\hline Hunted Game and Chicken & $0.500(0.986)$ & 0.046 & 0.613 & \\
\hline Fish and Beef & $0.674(0.977)$ & 0.068 & 0.492 & \\
\hline Market Carbohydrates & $-1.612(0.979)$ & -0.163 & 0.102 & \\
\hline $\mathrm{H}-\mathrm{SOL}$ & $-0.300(0.229)$ & -0.137 & 0.192 & \\
\hline T-SOL & $-1.948(2.265)$ & -0.079 & 0.392 & \\
\hline M-SOL & $2.914(4.494)$ & 0.062 & 0.518 & \\
\hline
\end{tabular}

${ }^{\mathrm{a}} \mathrm{SBP}$, systolic blood preassure; DBP, diastolic blood pressure.;

${ }^{\mathrm{b}}$ Comparisons are statistically significant at: ${ }^{*} p \leq 0.001 ; * * p<0.01 ; * * * p<0.05$;

${ }^{\mathrm{c}}$ Sex: $0=$ Male, $1=$ Female.

(e.g. mobile phones and TVs) and have houses with modern features (e.g. tin roofs and electricity) tend to eat more market-type foods (e.g. soda, cookies, and rice), refined carbohydrates and beef. Conversely, Shuar who consume fewer market food items (e.g. hunted game and local carbohydrate products) and own more traditional products (e.g. canoe and blowgun) maintain a subsistence lifestyle with limited consumer goods. This study demonstrated partial support of our third hypothesis, which proposed that the consumption of market-based foods and the ownership of consumer goods associated with greater MI would be linked to adverse cardiovascular and metabolic health markers. For example, greater consumption of chicken is associated with higher LDL levels, which suggests that Shuar may be adopting dietary practices that afford greater access to animal-based products that are high in protein but also high in unhealthy fats (e.g. when chicken is fried). Contrary to our expectation, higher HDL levels were also associated with degree of household MI. While speculative, this finding may be a result of increased dietary diversity among households with more market resources. For example, rather than relying on a few staple carbohydrate products (e.g. yucca and plantains), households with greater MI may have more consistent opportunities to acquire a variety of fruits and vegetables sold in markets as well as protein-rich foods, thereby influencing their HDL levels.

\section{Study limitations}

This study has several limitations. First, participant sample sizes were uneven between the UV and CC groups (254 vs 94), which restricted our ability to conduct separate multivariate analyses for the Shuar groups, particularly separate principal component analyses of the food frequency data. This issue limited our capacity to examine how the relationships between dietary factors, lifestyle measures and 
cardiovascular and metabolic health markers varied between Shuar in different environments. Additional cardiovascular and metabolic health data were collected from CC Shuar during summer 2012, which will be used in future analyses to address these issues. Second, the present study used a food frequency questionnaire to assess dietary patterns, but, as applied in this population, it does not provide reliable quantitative information on intake of energy (calories) or nutrients (e.g. protein, salt or saturated fat). This limits our ability to link the intake of particular food items with health measures. Future research will include 24-hour diet recall measures in order to capture additional quantitative information about the Shuar diet. Third, while standard ethnographic and analytical procedures (Bindon et al. 1997; Leonard et al. 2002) were implemented to capture lifestyle variations among Shuar, the authors recognize that the SOL measures used in the present study provide an imperfect and limited representation of MI. However, despite these concerns, the present study attempts to identify culturallygrounded indices of material lifestyle differences among Shuar. In our future research, we plan to refine our current techniques as well as add supplemental measures of MI to enrich our understanding of the cultural and economic changes experienced by Shuar. Fourth, this study primarily focused on Shuar from small rural communities (with $\leq 500$ community members) but did not include Shuar who have grown up or lived in towns or cities, such as Sucúa, for substantial portions of their lives. Shuar from towns may experience more pronounced dietary and lifestyle changes associated with even greater levels of MI, along with increased risks of CVD. Finally, the present study evaluated the links between culture change and health using crosssectional data, but this approach is limited in its ability to make causal links and to detect trends over time (Godoy et al. 2005). Our ongoing research is in the process of addressing all of these issues.

\section{CONCLUSIONS}

Previous studies suggest that there are several pathways by which cultural and economic changes impact individual health, including behaviour, healthcare and psychosocial stress, yet researchers disagree on whether the transitions associated with MI produce negative, positive or mixed effects on the health of individuals experiencing these changes. The present study provides evidence of variability in health, diet and lifestyle factors among Shuar, an indigenous population from the lowland regions of Amazonian Ecuador who are experiencing rapid MI. This research also paints a complex picture of the effects of MI on cardiovascular and metabolic health and suggests that MI does not necessarily lead to universally negative health changes in chronic disease. By collecting and evaluating data on multiple levels, including the individual, the household, the community and the region, this study is a first step in documenting the multi-faceted and dynamic processes of MI in southeastern Ecuador, thereby developing a more complete understanding of health in the context of cultural and economic change.

\section{ACKNOWLEDGEMENTS}

We thank our numerous research assistants and friends who helped make this research possible (Ruby Fried, Tiffany Gandolfo, Luzmilla Jempeket, Estella Jempeket, Cesar Kayap, Oswaldo Mankash and Medardo Tunki), the University of Oregon, the Federacion Interprovincial de Centros Shuar (FICSH), the Area 6 Ministerio de Salud Publico, John Tooby and Leda Cosmides of the Center for Evolutionary Psychology who helped fund establishment of the research site and initiation of this research and, most of all, our study participants. This study was funded by Wenner-Gren Foundation for Anthropological Research (Grant No. 7970), NSF (BCS-0925910 and BCS-0824602), Ryoichi Sasakawa Young Leaders Fellowship Fund, L.S.B. Leakey Foundation, NIH DP1OD000516-04 (via UCSB Center for Evolutionary Psychology, University of Oregon), University of Oregon Institute of Cognitive and Decision Sciences and University of Oregon Summer Research Awards.

Declaration of interest: The authors report no conflicts of interest. The authors alone are responsible for the content and writing of the paper.

\section{REFERENCES}

Baker PT, Hanna JM, Baker TS, editors. 1986. The changing Samoans: behavior and health in transition. Oxford: Oxford University Press. Berry JW, Trimble JE, Olmedo EL. 1986. Assessment of acculturation. In: Lonner W, Berry JW, editors. Field methods in cross-cultural research. Thousand Oaks, CA: Sage Publications. p 24.

Bindon J. 1995. Polynesian responses to modernization: overweight and obesity in the South Pacific. In: de Garine I, Pollack N, editors. Social aspects of obesity. London: Gordon and Breach. p 25.

Bindon J. 2007. Biocultural linkages - Cultural consensus, cultural consonance, and human biological research. Coll Anthropol 1:3-10.

Bindon J, Knight A, Dressler WW, Crews D. 1997. Social context and psychosocial influences on blood pressure among American Samoans. Am J Phys Anthropol 103:7-18.

Blackwell AD, Gurven MD, Sugiyama LS, Madimenos FC, Liebert MA, Martin MA, Kaplan HS, Snodgrass JJ. 2011. Evidence for a peak shift in a humoral response to helminths: age profiles of IgE in the Shuar of Ecuador, the Tsimane of Bolivia, and the U.S. NHANES. PLoS Negl Trop Dis 5:e1218.

Blackwell AD, Pryor G, III, Pozo J, Tiwia W, Sugiyama LS. 2009. Growth and market integration in Amazonia: a comparison of growth indicators between Shuar, Shiwiar, and nonindigenous school children. Am J Hum Biol 21:161-171.

Blackwell AD, Snodgrass JJ, Madimenos FC, Sugiyama LS. 2010. Life history, immune function, and intestinal helminths: trade-offs among immunoglobulin E, C-reactive protein, and growth in an Amazonian population. Am J Hum Biol 22:836-848.

Cepon TJ, Liebert MA, Urlacher SS, Snodgrass JJ, Madimenos FC, Sugiyama LS. 2012. The Shuar health and life history project: the effects of market integration on intestinal helminth levels among the Shuar of Amazonian Ecuador. Am J Hum Biol 24:222.

Chobanian AV, Bakris GL, Black HR, Cushman WC, Green LA, Izzo JL, Jr, Jones DW, Materson BJ, Oparil S, Wright JT, Jr, Roccella EJ. 2003. The National High Blood Pressure Education Program Coordinating 
Committee. Seventh report of the Joint National Committee on prevention, detection, evaluation, and treatment of high blood pressure. Hypertension 42:1206-1252.

CODENPE. 2012. Nacionalidad Shuar. Available online at: http://www. codenpe.gob.ec/index.php?option $=$ com_content\&view $=$ article\&id $=281 \&$ Itemid $=632$, accessed 5 May 2012.

Dennett G, Connell J. 1988. Acculturation and health in the highlands of Papua New Guinea. Curr Anthropol 29:273-299.

Descola P. 1994. In the society of nature: a native ecology in Amazonia. Cambridge: Cambridge University Press.

Descola P. 1996. The spears of twilight: life and death in the Amazon Jungle. New York: New Press.

Dressler WW. 1999. Modernization, stress, and blood pressure: new directions in research. Hum Biol 71:583-605.

Dressler WW. 2004. Culture, stress, and cardiovascular disease. In: Ember CR, Ember M, editors. Encyclopedia of medical anthropology: health and illness in the World's cultures. New York: Kluwer Academic/Plenum Publishers. p 8.

Dressler WW, Bindon JR. 2000. The health consequences of cultural consonance: cultural dimensions of lifestyle, social support, and arterial blood pressure in an African American community. Am Anthropol 102:244-260.

Dressler WW, dos Santos J, Gallagher P, Jr, Viteri F. 1987. Arterial blood pressure and modernization in Brazil. Am Anthropol 89:389-409.

Durnin J, Womersley J. 1974. Body fat assessed from total body density and its estimation from skinfold thickness: measurements on 481 men and women aged from 16-72 years. Brit J Nutr 32:77-97.

Foster Z, Byron E, Reyes-García V, Huanca T, Vadez V, Apaza L, Pérez E, Tanner S, Gutierrez Y, Sandstrom B, Yakhedts A, Osborn C, Godoy R, Leonard WR. 2005. Physical growth and nutritional status of Tsimane' Amerindian children of Lowland Bolivia. Am J Phys Anthropol 126:343-351.

Friedlaender J, Howells W, Rhoads J. 1987. The Soloman Islands Project: a long-term study of health, human biology, and culture change. New York: Oxford University Press.

Gage TB. 2005. Are modern environments really bad for us? Revisiting the demographic and epidemiological transitions. Yearb Phys Anthropol 128:96-117.

Genuth S, Alberti KG, Bennett P, Buse J, Defronzo R, Kahn R, Kitzmiller J, Knowler WC, Lebovitz H, Lernmark A, Nathan D, Palmer J, Rizza R, Saudek C, Shaw J, Steffes M, Stern M, Tuomilehto J, Zimmet P. 2003. Follow-up report on the diagnosis of diabetes mellitus. Diabetes Care 26:3160-3167.

Godoy R. 2001. Indians, markets, and rainforests: theory, methods, analysis. New York: Columbia University Press.

Godoy R, Cardenas M. 2000. Markets and the health of indigenous people: a methodological contribution. Hum Organ 59:117-124.

Godoy R, Reyes-García V, Byron E, Leonard WR, Vadez V. 2005. The effect of market economies on the well-being of indigenous people and on their use of renewable natural resources. Annu Rev Anthropol 34:121-138.

Gohdes D. 1995. Diabetes in North American Indians and Alaska Natives. In: National Diabetes Data Group, editors. Diabetes in America, 2nd ed. NIH Publication No. 95-1468. Bethesda, MD: National Institutes of Health. 683-701.

Gurven M, Blackwell AD, Rodríguez DE, Stieglitz J, Kaplan H. 2012. Does blood pressure inevitably rise with age? Longitudinal evidence among forager-horticulturalists. Hypertension 60:25-33.

Harner MJ. 1984. The Jivaro: people of the sacred waterfall. Berkeley, CA: University of California Press.

Hossain P, Kawar B, El Nahas M. 2007. Obesity and diabetes in the developing world-a growing challenge. $\mathrm{N}$ Engl J Med 356: 213-215.

Huss-Ashmore R, Schall J, Hediger M. 1992. Health and lifestyle change. Philadelphia, PA: University of Pennsylvania.

Kaplan N. 2002. Kaplan's clinical hypertension. $8^{\text {th }}$ ed., Philadelphia, PA: Lippincott Williams \& Wilkins.
Karsten R. 1935. The head-hunters of western Amazonas: the life and culture of the Jibaro Indians of Eastern Ecuador and Peru. Helsingfors: Societas scientiarum fennica.

Leonard WR, Galloway VA, Ivakine E, Osipova L, Kazakovtseva M. 2002. Ecology, health, and lifestyle change among the Evenki herders of Siberia. In: Leonard WR, Crawford MH, editors. Human biology of pastoral populations. Cambridge: Cambridge University Press. p 30.

Leonard WR, Snodgrass JJ, Sorensen MV. 2005. Metabolic adaptation in indigenous Siberian populations. Annu Rev Anthropol 34: 451-471.

Liebert MA, Snodgrass JJ, Blackwell AD, Madimenos FC, Cepon TJ, Sugiyama LS. 2011. The Shuar Health and Life History Project: immunoglobulin E, C-reactive protein, and cardiovascular and metabolic health among the indigenous Shuar of Ecuador. Am J Hum Biol 23:264.

Liebert MA, Snodgrass JJ, Cepon TJ, Urlacher SS, Madimenos FC, Sugiyama LS. 2012. The Shuar Health and Life History Project: the relationship between market integration and diurnal salivary cortisol rhythms of children in an indigenous lowland Ecuadorian population. Am J Hum Biol 24:232.

Lindegärde F, Vessby B, Ahrén B. 2006. Serum cholesteryl fatty acid composition and plasmaglucose concentrations in Amerindian women. Am J Clin Nutr 84:1009-1013.

Lindegärde F, Widen I, Gebb M, Ahrén B. 2004. Traditional versus agricultural lifestyle among Shuar women of the Ecuadorian Amazon: effects on leptin levels. Metabolis 53:1355-1358.

Lohman T, Roche A, Martorell R. 1988. Anthropometric standardization reference manual. Campaign, IL: Human Kinetics Books.

Lu F. 2007. Integration in the market among indigenous peoples. Curr Anthropol 48:593-602.

Madimenos FC, Snodgrass JJ, Blackwell AD, Liebert MA, Sugiyama LS. 2011. Physical activity in an indigenous Ecuadorian foragerhorticulturalist population as measured using accelerometry. Am J Hum Biol 23:488-497.

Madimenos FC, Snodgrass JJ, Liebert MA, Cepon TJ, Sugiyama LS. 2012. Reproductive effects on skeletal health in Shuar women of Amazonian Ecuador: a life history perspective. Am J Hum Biol 24: $841-852$.

McDade TW. 2002. Status incongruity in Samoan youth: a biocultural analysis of culture change, stress, and immune function. Med Anthropol Q 16:123-150.

McDade TW, Nyberg CH. 2010. Acculturation and health. In: Muehlenbein MP, editor. Human evolutionary biology. New York: Cambridge University Press. p 21.

McGarvey ST, Bindon JR, Crews DE, Schendel DE. 1989. Modernization and adiposity: causes and consequences. In: Little MA, Haas JD, editors. Human population biology: a transdisciplinary science. New York: Oxford University Press. p 17.

McSweeney K, Jokisch B. 2007. Beyond rainforests: urbanisation and emigration among lowland indigenous societies in Latin America. B Lat Am Res 26:159-180.

National Cholesterol Education Program (NCEP) 2001. Executive summary of the third report of the National Cholesterol Education Program (NCEP) expert panel on detection, evaluation, and treatment of high blood cholesterol in adults (Adult Treatment Panel III). JAMA-J Am Med Assoc 285:2486-2497.

O’Dea K. 1991. Westernization and non-insulin dependent diabetes in Australian Aborigines. Ethnic Dis 1:171-187.

Pavan L, Casiglia E, Braga L, Winnicki M, Puato M, Pauletto P, Pessina A. 1999. Effects of a traditional lifestyle on the cardiovascular risk profile: the Amondava population of the Brazilian Amazon. Comparison with matched African, Italian and Polish populations. J Hypertens 17: 749-756.

Piperata BA, Spence JE, Da-Gloria P, Hubbe M. 2011. The nutrition transition in Amazonia: rapid economic change and its impact on growth and development in Ribeirinhos. Am J Phys Anthropol 146: $1-13$. 
Pollard TM. 2008. Western diseases: an evolutionary perspective. Cambridge: Cambridge University Press.

Resnick HE, Jones K, Ruotolo G, Jain AK, Henderson J, Lu W, Howard BV. 2003. Insulin resistance, the metabolic syndrome, and risk of incident cardiovascular disease in nondiabetic American Indians: the Strong Heart Study. Diabetes Care 26:861-886.

RimmEB, GiovannucciEL, Stampfer MJ, ColditzGA, Litin LB, WillettWC. 1992. Reproducibility and validity of an expanded self-administered semiquantitative food frequency questionnaire among male health professionals. Am J Epidemiol 135:1114-1126.

Rubenstein S. 2001. Colonialism, the Shuar Federation and the Ecuadorian state. Environ Plann D 19:263-293.

Rubenstein S. 2002. Alejandro Tsakimp: a Shuar healer in the margins of history. Lincoln, NE: University of Nebraska Press.

Rutishauser IHE, Black AE. 2002. Measuring food intake. In: Gibney MJ, Vorster $\mathrm{HH}$, Kok FJ, editors. Introduction to human nutrition. Oxford: Blackwell Science. p 24.

Santos RV, Coimbra Júnior CE. 1991. Socioeconomic transition and physical growth of Tupi-Monde Amerindian children of the Aripuana Park, Brazilian Amazon. Hum Biol 63:795-819.

Shephard R, Rode A. 1996. The health consequences of 'modernization': evidence from circumpolar peoples. Cambridge: Cambridge University Press.

Snodgrass JJ, Leonard WR, Sorensen MV, Tarskaia LA, Mosher MJ. 2008. The influence of basal metabolic rate on blood pressure among indigenous Siberians. Am J Phys Anthropol 137:145-155.

Snodgrass JJ, Sorensen MV, Tarskaia LA, Leonard WR. 2007. Adaptive dimensions of health research among Indigenous Siberians. Am J Hum Biol 19:165-180.

Sorensen MV, Snodgrass JJ, Leonard WR, McDade TW, Tarskaya LA, Ivanov KI, Krivoshapkin VG, Alekseev VP. 2009. Lifestyle incongruity, stress, and immune function in indigenous Siberians: the health impacts of rapid social and economic change. Am J Phys Anthropol 138:62-69.

Sorensen MV, Snodgrass JJ, Leonard WR, Tarskaya LA, Ivanov KI, Krivoshapkin VG, Spitsyn V. 2005. Health consequences of postsocialist transition: dietary and lifestyle determinants of plasma lipids in Yakutia. Am J Hum Biol 17:576-592.

Steffen PR, Smith TB, Larson M, Butler L. 2006. Acculturation to western society as a risk factor for high blood pressure: a metaanalytic review. Psychosom Med 68:386-397.

Stirling MW. 1938. Historical and ethnographical material on the Jivaro Indians. Washington, DC: U.S. Government Printing Office.

Tabachnick BG, Fidell LS. 2012. Using multivariate statistics. 6th ed., Upper Saddle River, NJ: Pearson Education.

Tavares EF, Vierira-Filho JPB, Andriolo A, Sanudo A, Gimeno SGA, Franco LJ. 2003. Metabolic profile and cardiovascular risk patterns of an Indian tribe living in the Amazon region of Brazil. Hum Biol 75:31-46.

Valeggia CR, Burke KM, Fernandez-Duque E. 2010. Nutritional status and socioeconomic change among Toba and Wichí populations of the Argentinean Chaco. Econ Hum Biol 8:100-110.

Vasunilashorn S, Crimmins EM, Kim JK, Winking J, Gurven M, Kaplan H, Finch CE. 2010. Blood lipids, infection, and inflammatory markers in the Tsimane of Bolivia. Am J Hum Biol 22:731-740.

Waldron I, Nowotarski M, Freimer M, Henry JP, Post N, Witten C. 1982. Cross-cultural variation in blood pressure: a quantitative analysis of the relationships of blood pressure to cultural characteristics, salt consumption and body weight. Soc Sci Med 16:419-430.

World Health Organization (WHO). 2000. Obesity: preventing and managing the global epidemic. Geneva: World Health Organization.

World Health Organization (WHO). 2002. Reducing risks, promoting healthy life. Geneva: World Health Organization.

World Health Organization (WHO). 2008. The global burden of disease: 2004 update. Geneva: World Health Organization.

World Health Organization/International Society of Hypertension (WHO/ISH) 2003. 2003 World Health Organization (WHO)/ International Society of Hypertension (ISH) statement on management of hypertension. J Hypertens 21:1983-1992.

Zapata-Ríos G, Urgilés C, Suárez E. 2009. Mammal hunting by the Shuar of the Ecuadorian Amazon: is it sustainable? Oryx 43: $375-385$. 